\title{
SOME JURISPRUDENTIAL IMPLICATIONS OF ELECTRONIC DATA PROCESSING
}

\author{
ReEd Drckerson*
}

\section{INTRODUCTION}

The possibility of using computers to perform some of the significant operations that lawyers have traditionally performed has piqued the interest or enthusiasm of a few lawyers, stirred profound apathy in many, and angered or frightened the rest. For present purposes this third group is the most interesting. What is there to fuss about?

That a fuss is being made was shown by the reception accorded Reed C. Lawlor, a patent lawyer, and Fred Kort, a professor of political science, at the Second National Law and Electronics Conference, held at Lake Arrowhead in May 1962. The subject of the controversy, which continued in San Francisco ${ }^{1}$ and then spilled over into the legal periodicals, ${ }^{2}$ was a presentation of two different systems, each in a developmental stage, with the common objective of predicting the outcome of pending judicial proceedings. For the most part, the efforts focused on a relatively narrow field of the law: the right-to-counsel cases as considered by the United States Supreme Court. Each system involved a mathematical analysis and description of how the Supreme Court's grant or denial of relief, and the views of the individual justices, have been related to the respective presence or absence of a large number of specific fact elements (such as the immaturity of the defendant and the capital nature of the alleged crime) that the Court has recited as affecting the outcome of such cases. Other fields of investigation have included involuntary confessions and workmen's compensation.

Several of the participating law professors reacted to the presentation somewhat as members of the Daughters of the American Revolution would to two proponents of communism. What was significant for me was not their detection of particular flaws (flaws were not hard to find), but the high pitch of their professional and even moral indignation.

The specific objections to the elements of the two systems, some of which were well taken, have no particular relevance here. Because the structure of neither system is in issue in this discussion, it would make no difference even if both were ultimately found to be badly put together and wholly impracticable. Certainly, I

* A.B. I93 I, Williams College; LL.B. 1934, Harvard University; LL.M. 1939, J.S.D. 1950, Columbia University. Professor of Law, Indiana University. Chairman, Electronic Data Processing Committee, National Conference of Commissioners on Uniform State Laws.

${ }^{1}$ Using Computers to Predict Supreme Court Decisions, program of the Special Committee on Electronic Data Retrieval of the American Bar Association, August 7, 1962, in which Professor Fred Kort of the University of Connecticut, Reed C. Lawlor of the Los Angeles bar, and Chief Justice Frank R. Kenison of New Hampshire participated.

${ }^{3}$ See, e.g., Wiener, Prediction by Computers: Nonsense Cubed-and Worse, 48 A.B.A.J. 1023 (1962). 
have no intention of trying to vindicate these systems. That is for another occasion and for critics better qualified than I to evaluate them.

Of more immediate interest is the clear implication, drawn both from the specific objections and the emotional atmosphere in which some of them were made, that even if the systems could be rid of their specific flaws the very undertakings themselves subverted the basic values of our common law system. ${ }^{3}$ The object of this antipathy seemed to include both the use of machines and the use of mathematics or symbolic logic to solve legal problems.

Why was this revulsion so intense? For one thing, any use of a machine immediately suggests a surrender to slot-machine justice, which needs no new excoriation here. ${ }^{4}$ The specter is that of a mysterious and therefore alien being operating a mysterious and therefore alien system of decision competitive with the traditional methods of using case precedent. Who would wish to subvert the time-tested processes of the common law?

At the second conference, the broadest gauged yet most representative lay criticisms of the potential legal impact of the use of computers were made by Carl F. Stover. ${ }^{\sigma}$ Conceding that electronic techniques offer valuable aids in extending the reach of the lawyer in handling large scale information and performing "more rapid and thorough analysis of legal operations," Stover predicted that the effects on the legal system itself would not end there and suggested that the additional effects might not be altogether wholesome.

A major danger in all this, he said, is that we will refine legal techniques for their own sake. Another is that we will use inadequate indexing patterns and inadequate logical languages. Furthermore, he asked, is the amount of refinement in legal techniques that electronic systems promise desirable? Too much perfection, "far from freeing the mind of the jurist for 'the higher questions' as some claim, may enslave him to routinized formulas.... The effect of improved electronic systems may be to qualify the mediocre and discourage the great."

Worst of all, technology teaches its own ideas and methods. "In permitting the technical reason of the computer to invade the realm of law are we giving up anything vital? Are legal and technical reason the same?... Is the nature of the law such that it can be subjected to the precise formulations of mathematical logic without distortion?"

Technology, said Stover, hates man. "Man is the only agent that continues, by his very nature, to oppose the reign of reason as technique projects it." Unfortunately, ... unable to find the judicial principles that could bring technology under control, we have made law into a system of rules in the service of technology.

sor a broad discussion of the impact of modern technology on the law, sec Mayo, The New Technology and National Goals: Some Implications for Legal-Policy Decision Making, 37 Notre Dame LAw. 33 (Ig6r).

This was well done by Dean Roscoe Pound in Mechanized Jurisprudence, 8 CoLum. L. Rev. 605 (1908).

Stover, Implications of Information Retrieval to the Preservation of a Free Society (to be published in a forthcoming issue of MODERN UsEs of Locic in LAw [M.U.L.L.]. 
The ultimate expression of the absorption of law by technique will be the delegation of judicial decision to computers.... The notion that the majesty and mystery of the human experience, which is of the essence in law, can be written into a computer affronts the dignity of man.

$\ldots \ldots$

... we dismiss too lightly the great humane idea of justice, whose ambiguities and richness of meaning afford us precisely that power to deal with the human situation.

These are strong words. Because they form an excellent synthesis of views that are widely held, they warrant the most careful weighing. The central question that they raise is whether there is a fundamental, irreconcilable hostility between law and technology. Here we must distinguish between the direct impact of technology on the society with which law deals and the use of technology within the processes of the law itself. Although it may be too late to ask whether a technological society is a good one, there is still time to ask whether it is desirable to absorb any more of technology, electronic or otherwise, into the law itself. This question will be our main preoccupation.

Before we examine the potential benefits and dangers of computers and of the mathematical and logical systems that they reflect, it may be helpful to recite briefly some of the routine operations, common to lawyers and others, that computers are capable of performing. These include adding, subtracting, counting, identifying, sorting, arranging, storing ("remembering"), comparing, and retrieving. These capabilities, and particularly their general capacity to manipulate symbols in the ways required by propositional calculus and the algebras of modern logic, make them potentially useful for storing and retrieving legal and factual materials and for testing the internal consistency of systems such as particular bodies of legal doctrine and the internal structure of statutes. This latter utility in turn makes them inviting subjects for experimentation in the fields where stare decisis plays some part, and thus makes them potential bases for predicting judicial behavior.

The jurisprudential issues raised by electronic data processing and digital computers also touch the mathematical and logical systems on which they depend and the wide array of devices that modern technology offers as possible means to alleviate the problems that harass today's lawyer.

I approach these matters with misgivings, because an adequate treatment calls for the insights of a professional jurisprude and the expertise of an accomplished mathematician or logician. Unfortunately, I am none of these. Worse, it calls for a depth of investigation and scholarship that is impossible to realize within the time limits imposed by this symposium. Instead, I must be content with making a few general comments on the current need to effect a closer understanding between law and technology. If this can be accomplished, perhaps a rapprochement can be developed that will benefit both without exacting a significant sacrifice of either.

Let us begin by examining the principal reasons why lawyers are so reluctant to turn to modern technology for help. 
The Basic Fears

\section{A. The First Fear: Technology Expresses an Alien Philosophy}

The most interesting aspect of many analyses of electronics in the law is the assumption that there is a substantive philosophy in technology and that it is foreign and even antagonistic to the substantive philosophy of our legal system. "Science says this." "Technology does that." An entity that speaks or acts presumably expresses its own substantive philosophy. In this vigorous personification of "Technology," we have the new anthropomorphism. It is ironical that in an age in which the concept of God is commonly considered indigestible, the hypostatization of Science is swallowed by many without so much as an intellectual belch.

The notion that "Technology" is some kind of organic entity with a substantive philosophy of its own needs examination. First of all, "Technology" is not an organic entity, any more than "Science" is. Man-made, it gives effect to whatever philosophies particular men have put into it. If some technicians have given effect to wrong philosophies, this hardly commits the lawyers to doing likewise.

Even apart from spurious personifications, branches of science or technology such as mathematics and symbolic logic are conventionally viewed as embodying independent, and therefore potentially competing, bodies of substantive principle. This is reflected in the oft-made statement, which always intrigues, that such-and-such "is as true as two plus two equals four," a relationship that is only a tautology in the syntax of the language of whole numbers. ${ }^{6}$ If the basic facts about mathematics and logic could be made more explicit and less mysterious, there might be less blind worship among the gullible and less abhorrence among the skeptical.

If my information is correct, symbolic logic and mathematics are essentially no more than precise and less ambiguous languages, systems of notation with which deductively logical operations are more efficiently and more rigorously performed than with conventional language. ${ }^{7}$ Accordingly, these media provide abstract systems into which any substantive content can be poured without necessarily contaminating it.

Unfortunately, some of the proponents of technical aids to the law have prejudiced their causes by failing to dispel the impression that their systems are substantively new approaches to old problems, when in fact (if I understand what Professor Kort and Mr. Lawlor are up to) most of them are merely trying to build more accurate and reliable mathematical models, ${ }^{8}$ manipulatable by machine, to portray or test (rather than replace) the traditional processes of decision.

But if "Technology" has a substantive philosophy inimical to the law, it certainly does not lie in the minds of the particular technicians, mathematicians, and logicians

- Alfred J. Ayer, language, Truth and Logic 85 (2d rev. ed. 1946).

${ }^{7}$ Sec, e.g., John H. Banks, Elements of Mathematics 7 (1956).

${ }^{8}$ See note I stipra. The importance of adequate model thinking by lawyers in the field of legal-policy problems is emphasized in Mayo, supra note 3 , at 56-67. 
who attended the two conferences at Lake Arrowhead. Moreover, it was they who expressed with the keener sensitivity and greater sophistication the fears that their wares might be misunderstood and misused by the lawyer. ${ }^{9}$

If there is any substantive bugaboo here, it lies in the fact that the languages of mathematics and symbolic logic are so foreign to most laymen that they can be used to disguise subversive ideas. By the same token, it would be possible to disseminate the tenets of communism in French and thus hide them from a person who knew only English. Does this indict the French language?

Is it wrong, then, to fear the development of a Frankenstein's monster? Not at all. But the significant dangers, I suggest, are more rudimentary and less glamorous.

First of all, two of the inherent and obvious characteristics of modern thought are its compartmentalization and specialization. Although these have advantages, they carry the dangers of the Babelization of the language and a confusion of underlying concepts. Some semantic confusion is inevitable, but much of it, unfortunately, has needlessly resulted from the human temptation to develop a special technical jargon beyond what is necessary to carry on the work of each specialty. No parade of examples is necessary to illustrate this tendency at work in medicine, military science, law, and almost any field we could name.

Penetrating these barriers is now a major problem. Perhaps it should not be surprising that, even after two extended conferences in which lawyers and technicians have attempted a spirited but friendly dialogue, little progress has been made in acquainting either group with the other's operations. Unfortunately, the most recent concerted attempt by the lawyers to explain their operations to the technicians aborted when, in trying to explain the fundamental jural postulates of the law, they talked about particular substantive legal principles instead of the legal process.

In the meantime, the general purveyors of mathematics, science, and technology have succeeded only too well in impressing and confounding the outsiders, including most lawyers. Not only have the pedagogues and apologists for technology impressed the layman with the mysteries and wonders of their respective fields, but they have by false implication detached and even alienated the principles by which they operate from those that govern the thoughts and operations of lawyers. No wonder, then, that the lawyers who jealously guard the processes of the common law are fearful and distrustful. Certainly they are well advised not to entrust those processes to disciplines whose essence, capabilities, and limitations they do not understand.

So long as mutual understanding is wanting, the lawyer will continue to distrust the technician. Because the gap is unnecessary and prevents a potentially fruitful exchange, it is high time that it be closed.

' See, e.g., comments of Benson, Tribus, Bar-Hillel, and Luhn in Law AND Electronics: The Churlenge of A NEW ERA 129-134, 137-139 (Jones ed. 1962), the proceedings of the First Law and Electronics Conference, Lake Arrowhead, California, October 21-23, 1960. 


\section{B. The Second Fear: Technology Demands a Closed System}

A second basic reason why lawyers fear technology is their belief that logic, technology's most basic tool, demands too high a price.

In view of modern Holmesiolatry, of course, any reference to "logic" in an article dealing with law requires a special apology. The need is well illustrated by this statement of Frederick Bernays Wiener: ${ }^{10}$

Over eighty years ago, Holmes, then at the Bar, published a work considered revolutionary, or nearly so: The Common Law. One sentence on his first page shook contemporary thinking; he wrote, "The life of the law has not been logic: it has been experience." Soon the thought became commonplace, the staple of thinking for the generation currently on the bench and for many of the generation now at the bar. Today, however, we need to be taught de novo that the life of the law has not been electronics either.

If I read this passage correctly, it must mean that logic and electronics are, at the very least, excluded from being "the life of the law." But are they also excluded from playing any other role in the law? If not, on what basis are they to be admitted?

Whether logic is "the life of the law" I do not particularly care to debate. (I suspect that it is not.) At the same time, I am persuaded that logic is not irrelevant to law nor a stranger to its intimate processes. By "logic," Holmes was plainly referring to deductive rather than inductive logic, the latter of which would be hard to separate from "experience." The opening paragraph of The Common Law asserts no more than that in the development of law under our common law system the main thing has not been deductive logic, but something else. This is not the same as trying to read deductive logic out of the law, or even to downgrade it.11 That Holmes placed a high value on deductive reasoning is apparent throughout his writings. ${ }^{12}$ That the depreciators of logic also place a high value on it is implied in their own, not always successful, attempts at coherence.

Despite the contempt in which it is professionally fashionable among lawyers to hold deductive logic, ${ }^{13}$ I find it hard to divorce the concept of deductive logic from that of consistency, and the concept of consistency, in turn, from that of equality. How can we properly defer to such principles as stare decisis (however circumscribed a role we wish to assign it), "a government of laws rather than of men," and "the

${ }^{10}$ Wiener, supra note 2 , at 1025 .

21 "The epigrams of Holmes to the effect that the [sic] "The life of the law has not been logic; it has been experience' and that '... a page of history is worth a volume of logic' have thoroughly searred the minds of every American law student of the past two generations." Allen, in LaW AND Elzcrronics: The Challenge of a New Era, op. cit. supra note 9, at I57.

22 "A careful survey of realist writings reveals that they were not denying the need for logical reasoning in law but were asserting the insufficiency of logic to account for legal processes." EDwiN W. Patterson, JuRisprudence: Men and Ideas of the LAw 545 (1953).

13 "... the anti-logic attitude has been a pervasive one among lawyers with the result that a whole profession that holds itself out to the public as expert in the art of communication has remained by and large oblivious to the most significant intellectual tools that have been developed during the past century for the analysis of communication." Allen, in LAw AND EIECTRONICs: THE Chazlenoz OF A NEW ERA, op. cit. supta note 9, at 157 . 
equal protection of the laws," without deferring to principles of consistency ${ }^{\text {14 }}$ Does not every attempt to make the laws fairer and more coherent imply some use of deductive logic? Morris Cohen answered this question in $1916^{15}$ and I see no need to redo what he did so well. It is enough to recall his observation that "the effort to assume this form of a deductive system underlies all constructive legal scholarship." ${ }^{.16}$ Deductive logic necessarily plays an important role in the law, ${ }^{17}$ and to that (here indeterminate) extent mathematics and even machines such as digital computers offer a potential and congenial usefulness.

The assumption of general judicial consistency made by the authors of the prediction systems already referred to has been criticized on the grounds that it overlooks (I) 5-4 decisions; (2) the varying quality of legal counsel; (3) the fact that the Supreme Court sometimes reverses itself; (4) developing trends toward overruling or change; and (5) new fact elements.

The vehemence with which some of these critics have attacked the expressed premise that judges are in the main consistent (a judgment, incidentally, with which Professor Karl N. Llewellyn, himself fearful of the misuse of mathematics, wrote a long treatise to confirm $)^{18}$ seems to imply that, apart from honest changes of mind, judges are intentionally, consciously, or chronically inconsistent. I could hardly imagine a more professionally insulting indictment of the judiciary. To assume that the typical judge does not make a conscientious, and for the most part successful, attempt at consistency (according to his own lights) is to impute to him a conscious attempt to be arbitrary, or a changeability like that imputed by humorists to the female sex. Judges are occasionally stupid. Some of them may be mediocre lawyers. But that any significant number of them are consciously inconsistent or, as a rule, unconsciously inconsistent I cannot bring myself to believe.

What I think many of these critics have been trying, however inartistically, to say is that the consistency inherent in deductive logic presupposes a closed system based on a set of frozen axioms, whereas it is well known that, in addition to sometimes changing their minds, judges often deviate from their earlier pronouncements to take account of new factors. But since no one considers a judge to be "inconsistent" merely because he changes a legal proposition to take account of a factor not previously encountered, why may not a system that relies in part on mathematics and even machines be both generally consistent and open ended?

14 "Law is forced to take on this character in order to accomplish its end fully, equally, and exactly; and in so far as it fails to perform its function fully, equally, and exactly, it fails in the end for which it exists. Law is scientific in order to eliminate so far as may be the personal equation in judicial administration, to preclude corruption and to limit the dangerous possibilities of magisterial ignorance." Pound, stipra note 4 , at 102.

${ }^{16}$ Cohen, The Place of Logic in the Law, 29 Harv. L. Rev. 622 (1916).

${ }^{10} I d$. at 624 .

17 "The lawyer and the judge can, and ordinarily do, reason in a way consistent with the rules of formal logic, without knowing those rules. They can, indeed, reach reasonable decisions (sometimes) without reasoning at all. Yet in the long run and for decisions which justify the expenditure of time and effort, they will get better results if they utilize the resources of logic, both formal and instrumental." Patterson, Logic in the Law, 90 U. PA. L. Rev. 875, 909 (1942).

${ }^{38}$ Kari N. Llewellyn, The Common Law Tradition-Deciding Appeals (1960). 
The lawyers are entirely sound in insisting on a growing and dynamic legal system based on fluid and adjustable hypotheses, but the tentativeness of a particular set of hypotheses need not compromise the attempt to attain internal consistency in that set. There is nothing about mathematics, symbolic logic, or the scientific method that conditions their use on the freezing of any specific set of hypotheses. Even computers can be, and are continually, reprogrammed. The only danger lies in the inertia that may inhere in a particular mechanical or electronic system. A system that involves a significant limitation of this kind should, of course, be rejected.

Wiener, among others, lays great stress upon the rather obvious fact that "no human being is or can be completely consistent."19 By this he implies that machines that purport to perform completely consistent deductive operations are thereby disqualified as aids to predicting human behavior. Such a position fails to recognize that even the best systems of prediction are fallible. Indeed, if a system of prediction became infallible it would cease to be a system of prediction and become an instrument of control. Second, it fails to recognize that every degree of inconsistency does not destroy the possibility of reliable prediction but only affects its tentativeness by decreasing, in the same general proportion, the probability of its realization. Third, it fails to recognize that the play-in-the-joints necessary to wholesome legal growth need reside only in the tentativeness of specific hypotheses, the looseness of specific semantic relationships, and the play of induction-not in any incoherence in the deductive reasoning process itself. Certainly, the mere presence of an inductive element in the reasoning process need not impair the integrity or weight of its deductive elements.

Moreover, the actual vagaries of judicial behavior are often exaggerated, especially by the use of oversimplified standards of consistency. Mr. Justice Brennan's vote to affirm the conviction in the Hutcheson contempt-of-Congress case, after he had sided with an unbroken succession of seven convicted contemnors, ${ }^{20}$ hardly compels the conclusion that the Justice's contributions in this area are unpredictable or even inconsistent. Who is to say whether a series of bare decisions is or is not inconsistent until he has checked it against all plausible legal rationales? Indeed, it may turn out to be one of the most beneficial uses of mathematical models and machine analysis that they are helpful in unearthing and describing previously unarticulated legal rationales whose application in concrete cases has been obscured by surface incoherence.

\section{The Third Fear: Technology Leads to Professional Abdication}

Implicit in many of the protests against the possible use of symbolic logic, mathematics, or electronic computers in the law is the notion that reliance on such media requires the lawyer or judge to forfeit his professional judgment. Why this is so is not explained, but I suspect that many have read into the ineptitudes of the lazy or unsophisticated a law of nature.

${ }^{10}$ Wiener, supra note 2, at 1024. (Emphasis added.)

${ }^{20}$ Id. at 1025. Hutcheson y. United States, 369 U.S. 599 (1962). 
Even so, there is real danger here. A preoccupation with the beauties and efficiencies of technology, while not demanding as its price the abdication of professional judgment, often results in such an abdication. The beguilements of technology are considerable; and it is easy to forget that for the law, at least, it is a means and not an end in itself. Nor are these beguilements limited to tangible gadgetry. It is even possible that some of the recent applications of symbolic logic to legal problems have wandered off the path because the attractions of the system have led its proponents to overlook the naïveté of some of their semantic assumptions. But is such a risk new? And is it so formidable that we must abandon further discourse with the scientists, mathematicians, and technicians? If the possibility of abuse is a mortal defect, the law is in a bad way. It is undoubtedly true, as Morris Cohen has said, that "Like other useful instruments, logic is very dangerous, and it requires great wisdom to use it properly."21 But can the law afford, merely on this account, to repudiate logic?

Everything that can be said of the electronic computer in this regard can be said also of the legal form book, even of the office form that the lawyer has painstakingly hammered out in the course of his own professional experience. What greater trap for the careless, lazy, or unwary draftsman, pleader, brief writer, or other legal craftsman than the standardized provision! Yet, despite this, lawyers continue to use legal boilerplate, and few voices have been raised to protect the public on this account.

Should lawyers refrain from using legal boilerplate? They cannot operate efficiently without it. Indeed, they cannot operate even inefficiently without it. The danger in prefabricated legal text is not that all forms are bad, but that even good forms can be bad if they are used indiscriminately or without a thorough grasp of the specific objectives that they are intended to serve in the particular case. This is the main danger in computers. This is the main danger in mathematics. This is the main danger in statistics, accounting, and many other fields affecting the lawyers' practice that are presided over by specialists operating within their own private linguistic and conceptual domains. The objection to a mechanized form book that was recently developed is not so much that it is mechanized as that it is being marketed under the representation that it produces, not a tentative draft, but a "final instrument." Here, indeed, is an invitation to professional abdication.

On the other hand, there should be nothing inherently shocking, even to common law lawyers, in the notion that it may be possible to build mathematical models which so closely reflect the traditional deductive operations of the common law system of precedent in particular areas that these operations may be performed more accurately and more equitably without compromising the ultimate human judgment which lawyers and judges must forever reserve to themselves. This should be no more shocking than the notion that a lawyer can dictate the first draft of a brief or will into a dictating machine. The lawyer who does so hardly delegates the drafting of the instrument either to the machine or to the transcriber.

${ }^{21}$ Cohen, supra note $1_{5}$, at 638 . 
It is unfortunate that one of the advocates of electronic technology at Lake Arrowhead saw fit to press the claim that law is a "natural science." Even apart from the dubious merits of the contention, this was strategically a mistake because anyone who takes such a position immediately loses most of his legal audience. The point was not even in issue. The relevant question was not whether law is a natural science but whether particular aspects of the law could be enriched by the limited application of scientific methods without destroying the essential character of those aspects. There are many disciplines that could hardly be classed as sciences in the authentic sense but could be improved in some respects by a limited use of scientific procedures.

Because the conscientious lawyer must never permit insight and judgment to abdicate in favor of a machine, I like Martin Shubik's characterization ${ }^{22}$ of a computer as a "mechanized consultant." A consultant never makes the ultimate judgment or decision.

\section{The Fourth Fear: Technology Demands Too Much Precision}

A fourth basic reason why lawyers fear technology likewise relates to the supposedly exorbitant demands made by technological and mathematical logic.

This fear, which probably overshadows all others; is implicit in the statement that computerization, working through logic, challenges us "to fashion a language that will make it possible to preserve the richness of legal thought, the systematic ambiguity of critical legal concepts, and the normative aspects of legal standards. ... we dismiss too lightly the great humane idea of justice, whose ambiguities and richness of meaning afford us precisely the power to deal with the human situation."23

This challenge was capped with a question: "Is the nature of law such that it can be subjected to the precise formulations of mathematical logic without distortion?" The answer is plainly, No. But this may be the right answer to the wrong question. The question might better have been phrased: "Is the nature of mathematical logic such that law can be subjected to it without distortion?" or "Can the mathematicians and the computer experts operate with natural words and symbols without disturbing the vagueness of such words and symbols?" Vagueness, together with generality, is a rich resource of the law, and lawyers justifiably fear anything that might deprive them of it or materially hamper its use.

In the past, scientists have tended to treat vagueness as a disease of language, whereas to lawyers it is often a positive virtue that they will vigorously defend. Although mathematics and logic have in some respects a greater capacity for precision, it does not follow that a particular mathematical or other symbol is necessarily precise. ${ }^{24}$ Although mathematics consists of many separate systems for manipulating symbols, it is primarily concerned with the relationships between the

\footnotetext{
${ }^{22}$ Made at the second Lake Arrowhead conference.

${ }^{28}$ Stover, supra note 5 .

24 "... the rules of deductive (formal) logic are as true of propositions stated in vague terms as of propositions stated in precise terms." Patterson, supra note 17 , at 908.
} 
symbols themselves (the syntactic dimension), not the relationships between the individual symbols and the ideas to which they may respectively refer (the semantic dimension). For example, the vague word "reasonable" loses none of its vagueness if a special synonym such as " $\phi$ " is substituted for it for the purposes of analyzing a complicated paragraph. Professor Layman E. Allen has been using symbols to portray the permutations and combinations of multiple syntactical ambiguity, without in any wise disturbing the semantic content of particular terms. ${ }^{25}$ In such cases, it should be emphasized, the translation into symbolic form is for a very limited purpose.

I believe it no exaggeration to say that for the purposes of logical manipulation any idea that can be stated in conventional language can also be represented, without loss of vagueness or generality, in mathematical or symbolic terms. Let me hasten to add that "mathematical" does not necessarily represent an attempt to quantify. Boolean algebra, the logic of classes, is a good example.

If the compatibility of mathematics and semantic vagueness surprises many lawyers and some mathematicians, it is because it has been only in recent years that mathematics has been called on to serve the needs of disciplines whose references are often intentionally and properly vague. This realization has prompted at least one logician to reformulate the principle of the excluded middle, whose classic formulation apparently assumed that each term had a precise referent. ${ }^{26}$ It has also brought to light the potential usefulness of many-valued logic for building mathematical models helpful in dealing with problems of vagueness. In the meantime, the historical identification of mathematics with semantic precision has been mistakenly seen by many as inhering in mathematics.

If this analysis is correct, one of the worst of the lawyer's fears of mathematics and symbolic logic can be laid quietly to rest.

\section{E. The Fifth Fear: Technology Results in Overrefinement and Overcomplexity}

Is there danger of overrefining the law? Has the law already achieved the optimum of specificity? Would further refinement produce not only overrefinement but such a preoccupation with detailed rules that the fundamental principles of justice would be neglected? Would the legal system become unmanageable? If so, our legal system may already be in serious jeopardy. This is a commonly expressed fear. ${ }^{27}$

So far as a preoccupation with minute distinctions distracts wholesome attention from basic principles of equity and justice, refinement is indeed a danger. But not to refine adequately is also a danger. How can we administer justice in a world of almost infinite variety except with rules articulated to a vast complex of significant differences? The alternative, as discovered by federal agencies that attempted during World War II to maintain the American economy in all its rich variety, is to reduce

\footnotetext{
95 Allen, in LAw AND Electronics: The Challenge of a New ERA, op. cit. supra note 9, at i79-204.

sa Max Black, Language and Philosophy 55 (1949).

${ }^{27}$ See, e.g., Stover, supra note 5.
} 
it to more administratively manageable, though not necessarily more desirable, form. Is it not desirable to extend the administrative capacity of government to cope with the significant details of vastly more complicated human situations so that the government may carry out its responsibilities with less need to remake, for its own convenience, the institutions that it governs?

Apart from the general danger of distraction from essentials, the significant danger, it seems to me, is that the capacity to deal with an existing problem more effectively will become, instead of a solution, primarily an occasion for increasing the size of the problem.

This danger may be realized in many contexts. Is it not a common irony that specific cures often make possible the extension of the very diseases that they are designed to cure? Feeding an overcrowded country may encourage the breeding that increases the number of people who ultimately starve. Aid to the unemployed can increase the attractiveness of unemployment. New highways and other vehicular facilities often encourage the greater uses of automobiles as much as they lessen existing traffic pressures.

Similarly, extending the ability of government to deal with complicated human situations may invite it to participate where participation is now impracticable. That such an extension has already occurred is suggested by someone's estimate that, were the federal government to be deprived of its present computer equipment, the entire population of the United States would be needed to man the existing programs. Extending the government's reach can be good, but there are areas in which many people would prefer it to remain inactive, if not impotent.

The same dangers arise for information or document retrieval. Although the mounting flood of legal materials is forcing lawyers to adopt non-traditional methods of storage and retrieval, the same methods may be also used to store and retrieve a myriad of documents that it is now impossible or impracticable (and possibly even undesirable) to handle. If the computerized search of cases and statutes becomcs economically feasible, what is to keep us from indexing not only the existing sources now consulted by judges, but also heretofore unreported appellate cases and lower court decisions, the decisions of many administrative tribunals, and the legislative histories of even administrative regulations and municipal ordinances? Nothing, that is, but a wholesome grasp and balance of ultimate objectives.

But does the fact that cures are subject to abuse mean that we must submit to the disease? Should such a risk dissuade us from trying to solve our problems?

Instead, we should have some sense of what in optimum terms is ultimately desirable, and then muster the professional self-discipline to use such goals as guides in shaping specific solutions. Thus, when mechanized searching of the law becomes operational, we must be careful lest we do no more than duplicate present difficulties of search on successively higher and more refined planes of complexity, especially those in which the substantive benefits of further refinement are disproportionately small in relation to the added expense and effort. 
In these respects, electronic computers offer no danger not already inherent in almost every device we operate today. In distracting us from essentials, unnecessary refinements can undermine not only our legal system but our very civilization.

An alternative to computers is to reduce drastically the number and complexity of our problems. We might even try to standardize and simplify our society. More specifically, we might limit the amount of information available. In the law, for example, we might try to reduce the proportion of judicial opinions that are published. We might also refuse to maintain the legislative attics in which we accumulate all manner of unreliable scraps of federal legislative history. Here, it is ironical that some of those who are so keen to have the states emulate the federal practice of preserving every legislative scratch and doodle are indignant at the suggestion that present standards of record keeping and research are forcing us into a position where the question is no longer whether lawyers mechanize but how and to what extent. At the same time, we must not assume that the use of computers necessarily leads to greater refinements or complexities. Technology can also be used to simplify.

One of the most persuasive arguments against a specific use of technology in the law is that for the purposes of the particular problem, its language and methods are overelaborate. But whether an adequate mathematical model can be created and whether-if created-it is worth the effort and expense to program it for a computer, has no particular relevance here beyond the general point that a lawyer is always well advised not to use a method or device that is more complicated than his particular problem warrants.

\section{II}

\section{The Possible Benefits}

We have seen some of the important risks to the legal system from the use of computers and other tools of modern technology. Let us now see what benefits to the law they might be expected to produce.

This is not the occasion for pressing the claim that by entrusting the routine aspects of legal research and other legal functions to computers and other mechanical devices the lawyer will be freed to spend a larger proportion of his time on the aspects of his legal operations that call for close and personal professional judgment. The more efficient use of his time should, of course, make it possible not only to produce better results, but to produce them more cheaply and more efficiently. This should, among other things, help to improve the economic position of the bar. ${ }^{28}$

More significant for present purposes is the possibility, suggested by some, that computerization will help to bring about the further standardization of legal concepts and of legal terminology. But is further standardization desirable? Here,

\footnotetext{
${ }^{28}$ See Stumpf, in Law and Electronics: The Challenge of a New Ers, op. cit. supta note 9, at 46-67.
} 
it may be appropriate to include an excerpt from my recent correspondence with a member of the faculty of the University of Liège: ${ }^{29}$

... the need for standardization flows from the ideal of dealing with similar problems similarly. There are two competing pulls. On the one hand, the desire to adapt the law to the needs of a highly heterogeneous world tends toward uniqueness of treatment with a consequent multiplicity and complexity of specific rules. On the other hand, the desire for coherence and administrative feasibility tends toward emphasizing similarities and minimizing differences.... Without appropriate standardization of ideas, coherence in the law is impossible....

Because the use of computers extends the range of what is administratively feasible, the net result may be that, although greater standardization can be achieved in areas where greater systematization brings to light significant similarities that have previously been obscured, less standardization may in fact result where there are significant differences that computers now make it administratively feasible to reflect.

The same correspondence ${ }^{30}$ also discussed the relationship of computers to the standardization of language.

Despite a well established legal tradition that tends to subvert this idea, it is not merely desirable for the use of computers but essential that all things falling within the same class be designated similarly and that those falling within different classes be designated differently. Such a debabelization of the law is important even if computers are not to be used. There are few factors that cause more confusion in thinking inside and outside the law than our failure to pay scrupulous attention to consistency in designation....

Must we conclude from this that until the language of the law is made as consistent as the language that we call mathematics or symbolic logic we must defer the use of computers? Although it would greatly facilitate their use to make the current language of the law more consistent, it is not essential so long as the existing language is translated into consistent input language.

Thus, if the use of computers produces a greater standardization of concepts and legal terms, it will do so not so much because the standardization of concepts and of legal terms is a technical prerequisite to the use of computers as because the systematic treatment of the law makes it easier to ascertain those places where further standardization is desirable. "Standardization," of course, here refers to uniformity in a spatial rather than a temporal dimension. No notion of uniformity should be permitted to inhibit the sound development of the law.

The computer's ability to deal with complicated, detailed situations will probably make its greatest jurisprudential impact in other respects. One of these lies in storage and retrieval, where computers make possible much more detailed research than is now practicable. This added legal capability makes possible searches based on specific fact patterns independently of the legal rules involved. Although the idea of searching cases without immediate regard to the applicable rules of law

${ }^{20}$ How Should We Use Computers in Law?, de Moffarts-Dickerson correspondence, 62S M.U.L.L. 179, $18 \mathrm{I}(1962)$.

${ }^{\text {so }}$ Id. at $182-83$. 
may at first seem unnatural, further reflection suggests that this may turn out to be one of the most legally fruitful uses of computers in legal searching.

Such a search for similar fact situations makes sense because a lawyer is interested not only in favorable decisions but also in unfavorable ones with which he is likely to be confronted by his opponent. Moreover, such a search may well turn up relevant points of law that the searcher had not anticipated. Finally, in a rich field such as automobile liability, the searcher is not interested merely in searching in terms of the broad fact categories in which most legal rules are couched but in searching within those categories for the particular fact patterns that are the most like his own. Such a search has become routinely feasible only with the deep indexing ${ }^{31}$ that computerization or other modern mechanical aids makes possible..$^{32}$

Besides the obvious advantages of factual pinpointing, there may be important jurisprudential implications as well. These lie in the fact that point-of-law searching and fact searching are not so different in kind as they are in degree. Most substantive rules of law are ultimately statable in terms of a factual hypothesis ("protasis") followed by the simple affirmation that in such circumstances the plaintiff has or does not have a good cause of action. The main difference between a statement of fact and a statement of law is that, although both describe factual situations, the former is a generalized statement of a specific concrete occurrence, whereas the latter is a very general factual hypothesis to which legal consequences are said to attach.

This means that one of the most important differences between searching by point of law and searching on the facts lies in the differing degrees of generality of the fact categories concerned. But why does this difference in degree exist? An attempt to answer this question leads one to wonder whether the fact that the rules of law tend to postulate very general fact situations is not so much desirable in itself as it is a result of the inherent limitations of traditional methods of storing and retrieving legal information. Is it possible that the great generality of our specific legal rules has not resulted entirely from considerations of equity and justice, but partly from the accident of our previous inability to cope with greater degrees of doctrinal specificity? Certainly this inability has imposed severe limitations on the scope of legal treatises and digests.

Two possibilities are suggested. As one alternative, it may now be possible to develop, classify, and preserve more specific and detailed legal rules than have heretofore been practicable, without being overwhelmed by this proliferation to the point of losing sight of basic legal principles or the integrating objectives that the law is intended to serve. On the other hand, might it not also be possible to translate broad common law principles or rules into a general mathematical form which can be manipulated by machine, and thus to remove the need for a myriad of specific rules? The use of formulae is not uncommon in statutes and regulations.

\footnotetext{
- 31 Indexing by a large number of search terms.

${ }^{33}$ Dickerson, Electronic Computers and the Practical Lawyer, 14 J: Legal Ed. 485, 489 (xg6z).
} 
If feasible, such an approach would have the advantages of producing a simpler, more understandable, and more manageable legal system, less likely to befuddle the user, and at the same time more cleanly articulated to the subtly shifting hypotheses of concrete fact situations.

Although this may verge on what Yehoshua Bar-Hillel has called the "free flight of fantasy at its wildest recklessness, ${ }^{, 33}$ the richness of the rewards and the greater capacity to serve the ends of justice and equity may make it desirable not to dismiss the possibility summarily. After all, the present molds of the law may not have resulted entirely from calculated judgment, but may have been shaped partly by the limitations that the traditional methods of dealing with legal materials have accidentally imposed.

And while speculation still runs wild, let us look at another potential use of computers in the law. Although many of the current electronic systems are relatively crude or otherwise imperfect, there is some indication that many or most of their shortcomings are theoretically susceptible of being remedied and that, with improved programming, they can be made to operate substantially as claimed.

For example, it may now be feasible to exploit more completely some of the important assumptions of legal realism. One of these assumptions is that what a judge does is more important than what he says he does, and that greater insight into the course of the law is to be derived by examining the actual patterns of decision than by merely synthesizing a sequence of express judicial rationalizations.

The systems for predicting judicial behavior mentioned at the beginning of this article represent an attempt to describe how specific judges and specific courts react when confronted with particular kinds of fact situations mentioned as significant in the courts' opinions. Through the use of multiple regression equations it is now possible to develop weights that indicate how much force a judge has respectively been giving to the presence or absence of particular kinds of fact situations when dealing with a specific legal problem.

Although the systems of prediction mentioned earlier attempt primarily to predict whether the outcome of a particular controversy will be "pro" or "con," the same systems may be useful in developing mathematical, and ultimately natural-language, descriptions of the patterns of decision, showing the respective weights that the courts have in fact accorded the presence or absence of factual aspects mentioned by them as being relevant to their deliberations.

So far as the actual patterns of judicial decision may be relevant to a statement of the law or to the conditioning of the judicial process, a system such as that suggested might be valuable in testing the consistency of the decision patterns of particular judges or courts. It might also be used as a cross check on statements of judge-made law derived by more conventional means and-conceivably in appropriate circumstances-as a means of developing more accurate and more refined

${ }^{s 3}$ Bar-Hillel, The Future of Machine Translation, The Times (London) Literary Supplement, No. 3138, April 20, 1962, p. 268, col. 5 . 
rules or principles of law. This may not be wholly far-fetched, because, as we have seen, almost every rule of judge-made law is ultimately resolvable into a factual hypothesis to which is appended the legal conclusion that in such circumstances the plaintiff is or is not entitled to recover.

While these speculations may seem impractical to many, perhaps some will concede that the ideas and concepts that such approaches attempt to express are not substantively competitive with established approaches to the law, but expressive of them. Thus, in the systems described, there is an attempt to erect, not a substitute for the basic elements of judicial reasoning, but a more systematic and efficient way of carrying out what many have considered to be essential features of our traditional approaches to the common law. Only the intermediate terminology and the mechanical routines need to be different.

Perhaps the greatest and most obvious advantage of investigating, studying, and testing such techniques is the fuller understanding of our basic legal concepts that they will incidentally provide-helping us, among other things, to determine how fully our present assumptions rest on solid principle, and how fully they rest on historical accident or on the practical limitations inherent in the specific legal approaches heretofore used. Even if all the possibilities discussed in this article are ultimately found to be undesirable, impractical, or uneconomic, the law will have been enriched by the fresh insights into its operations that the exercise will have provided. No one can successfully program a problem for machine solution without developing a deep and detailed understanding of the substance of what he is dealing with. It is just such a benefit as Margaret Masterman had in mind when she recently wrote that the digital computer, with its ability to process nonnumerical data, provided the "telescope of the mind" that Leibniz had hoped for in a universal information-classifying system. ${ }^{34}$ The fact that the attempts at machine translation have, despite their meager successes, suggested new possibilities about the nature of language gives hint of the possibility of similar insights into the legal process. The possibility, envisaged by Hesse, ${ }^{35}$ of making a machine find analogies, offers an exciting basis for legal speculation. So, also, do the exercises now being conducted in the fields of games theory and decision theory.

However, the purpose of this article has been not to urge the adoption of any particular technological advance, but to urge that the current technological explosion and the increasing complexity of law that a vastly more complicated society is producing require the lawyer to enhance his methods to keep abreast of the legal problems that have so proliferated. Technology should interest the lawyer not merely because it has helped to create the problems that he now faces but because, properly and discriminatingly appraised, it offers strong promise of providing the practical means by which he can extend his capacity for dealing with them, fortunately without requiring him to sacrifice any significant principle of the common law.

'Masterman, The Intellect's New Eye, The Times (London) Literary Supplement, No. 3139, April 27,1962 , p. 284 , col. 2 .

${ }^{30}$ Id. 2 t 284 , col. 5 . 
Therefore, while we stay healthily wary of specific technological panaceas, let us continue our dialogue with the scientists, mathematicians, and technicians in hopes that sooner or later we can make clearer to them the nature of the legal process, while they in turn acquaint us sufficiently with their vast array of approaches, techniques, and equipment. May we not only select the best tools for the modern legal job, but also understand them sufficiently so that they will remain our servants and not become our soulless masters. 